
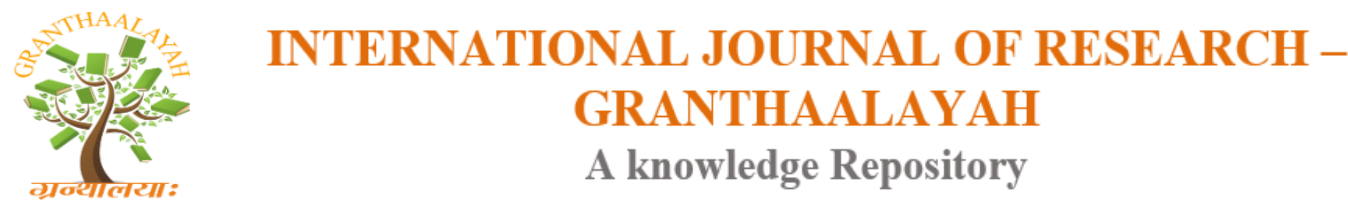

\title{
ANALYSIS OF PROPERTIES OF CONCRETE USING CRUSHED GLASS POWDER AS ADMIXTURE
}

\author{
Vishal Gadgihalli ${ }^{* 1}$, Ramya M S ${ }^{2}$, Abrar Khan ${ }^{3}$, Ranjitha ${ }^{1}$, Babitha Rani ${ }^{2}$ \\ ${ }^{*}$ UG Student, Department of Civil Engineering, Jain University, Bangalore, India \\ 2 Assistant Professor, Department of Civil Engineering, Jain University, Bangalore, India \\ ${ }^{3}$ UG Student, Department of Aerospace Engineering, Jain University, Bangalore, India
}

DOI: https://doi.org/10.29121/granthaalayah.v5.i4RASM.2017.3369

\begin{abstract}
Concrete admixture is added to enhance the properties of concrete to make its function as required. In this paper analysis of properties of concrete using of glass powder as admixture to concrete is studied and verified the strength of concrete and temperature emitted due to chemical reaction to the normal Portland cement. Using of glass powder as admixture the temperature emitted due to exothermal reaction of concrete has reduced. As glass has property of absorbing high temperature. This gives better results hence we can use this glass powder as an admixture. Where the reacting temperature and the emitting temperature place a crucial role in construction, and as glass powder is rigid and non-crystalloid solid this increase bond strength in concrete to increase its strength.
\end{abstract}

Keywords: Glass Powder; Temperature; Retarders; Admixture; Flexural Strength; Compressive Strength; Grade of Concrete.

Cite This Article: Vishal Gadgihalli, Ramya M S, Abrar Khan, Ranjitha, and Babitha Rani. (2017). "ANALYSIS OF PROPERTIES OF CONCRETE USING CRUSHED GLASS POWDER AS ADMIXTURE.” International Journal of Research - Granthaalayah, 5(4) RASM, 54-58. https://doi.org/10.29121/granthaalayah.v5.i4RASM.2017.3369.

\section{Introduction}

Glass powder is non-crystalline amorphous solid that is often transparent, white and has wide spread practical, technological and decorative usage applications. The silica of ass formed from a specific type of soda-lime glass, silicon dioxide, sodium oxide from sodium carbonate, calcium oxide from sodium carbonate, calcium oxide also called time. Silica is common fundamental constituent of glass [1]. However, its high melting temperature (17230) and viscosity make it difficult to work with [2]. Extremely clear glass, used for fiber-optic wave guides in communication networks [3]. As light losses through $1 \mathrm{~km}$ of glass fiber is 5\% its intensity [4]. 
Glass can be easily mold to any shape by melting it to its melting temperature. These are different types of glasses formed due to advancement

- Fused quartz

- Soda-lime silica glass

- Sodium baron silicate glass

- Lead-oxide glass

- Alumina silicate glass

- Germanium-oxide glass etc

The advancement of glass has made to increase its bond strength, now a day's glasses have strength to withstand the velocity of speed of bullet.

Glass are produced widely because they have good transparency to pass light through it, the glass can be reused, recycled. Glass can be manufactured to any color. Glass imposes a microscopically smooth surface. Glass powder has good bond strength within which increases strength of concrete if we see glass powder as admixture. Since very less number of literature found related to the present study, the author just compared his work with general ordinary Portland cement.

\section{Methodology}

The crushed glass powder collected from manufactures. This powder must not be exposed to sun light and other chemicals. Instead packing powder in aluminum sheets or polythene cover helps in protecting powder from atmospheric moisture. While mixing the powder must be free from lumps. Target strength of concrete was determined by the equation. Target strength $=f^{\prime}$ ck $=f c k$ +1.65 (s) - [eq1], according to the standard code from IS10262-2009. The amount of crushed glass powder was calculated from the following equation, volume of powder used $=$ (mass of chemical admixture/specific gravity of admixture *1000). The specific gravity of glass powder was found 1.54 by Le-Chatelier principle [5] [6].

The cube casted for the size $15 \mathrm{~cm} 3$. The compression and flexure strength were tested for 1,7 , 14, 21 and 28 days after casting.

An empty spaced cube with bottom size of $10 * 10 * 10 \mathrm{~cm}$ casted using concrete with glass powder concrete and walls of thickness $1 \mathrm{~cm}$. Water of 1000c was filled in empty cube and the time consumed for reduction of temperature of water to 400c were noted down. This gives the time consumed by cube to reduce inner temperature of $1000 \mathrm{c}$ of water to 400c.

An empty cube casted by using crushed glass powder concrete size $10 * 10 * 10$ was inserted into another larger empty cube casted using plane cement concrete size of $15^{*} 15^{*} 10 \mathrm{~cm}$. $3 \mathrm{~cm}$ sufficient space was left between two cubes was filled with Water of 100c and top side of cube was closed by lid. Water temperature was noted down after 8mins for 1, 7, 14, 21 and 28 days of similar casted samples. The difference between the water temperature noted after $8 \mathrm{~min}$ and the temperature at room temperature gives the amount of heat transmitted through the walls of inner cube. 
[Gadgihalli et. al., Vol.5 (Iss.4: RASM), April, 2017]

ICV (Index Copernicus Value) 2015: 71.21

Recent Advances in Sustainable Materials
ISSN- 2350-0530(O), ISSN- 2394-3629(P)

IF: 4.321 (CosmosImpactFactor), 2.532 (I2OR)

\section{Results and Discussions}

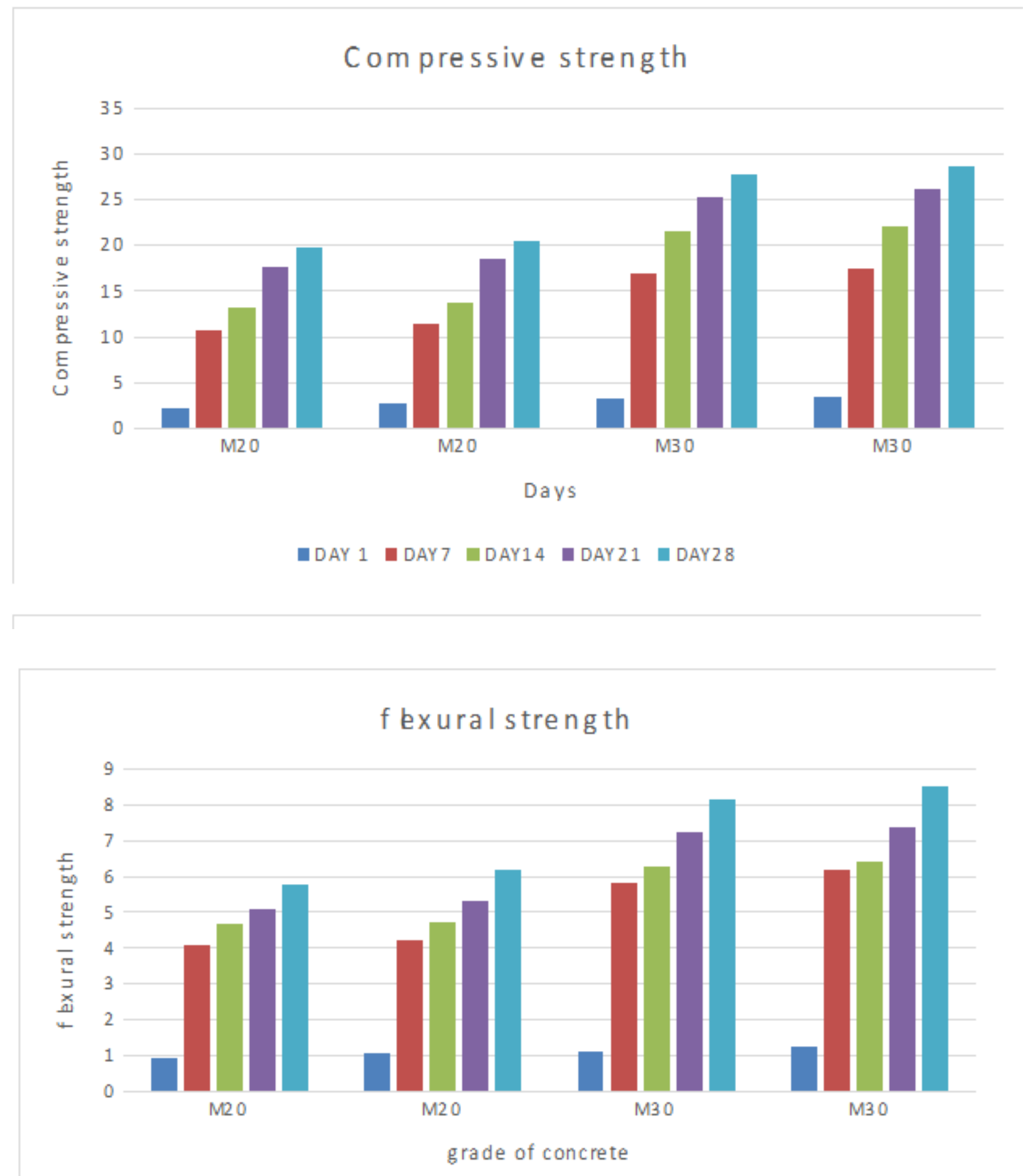

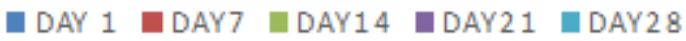


[Gadgihalli et. al., Vol.5 (Iss.4: RASM), April, 2017]

ICV (Index Copernicus Value) 2015: 71.21

Recent Advances in Sustainable Materials
ISSN- 2350-0530(O), ISSN- 2394-3629(P)

IF: 4.321 (CosmosImpactFactor), 2.532 (I2OR)

InfoBase Index IBI Factor 3.86

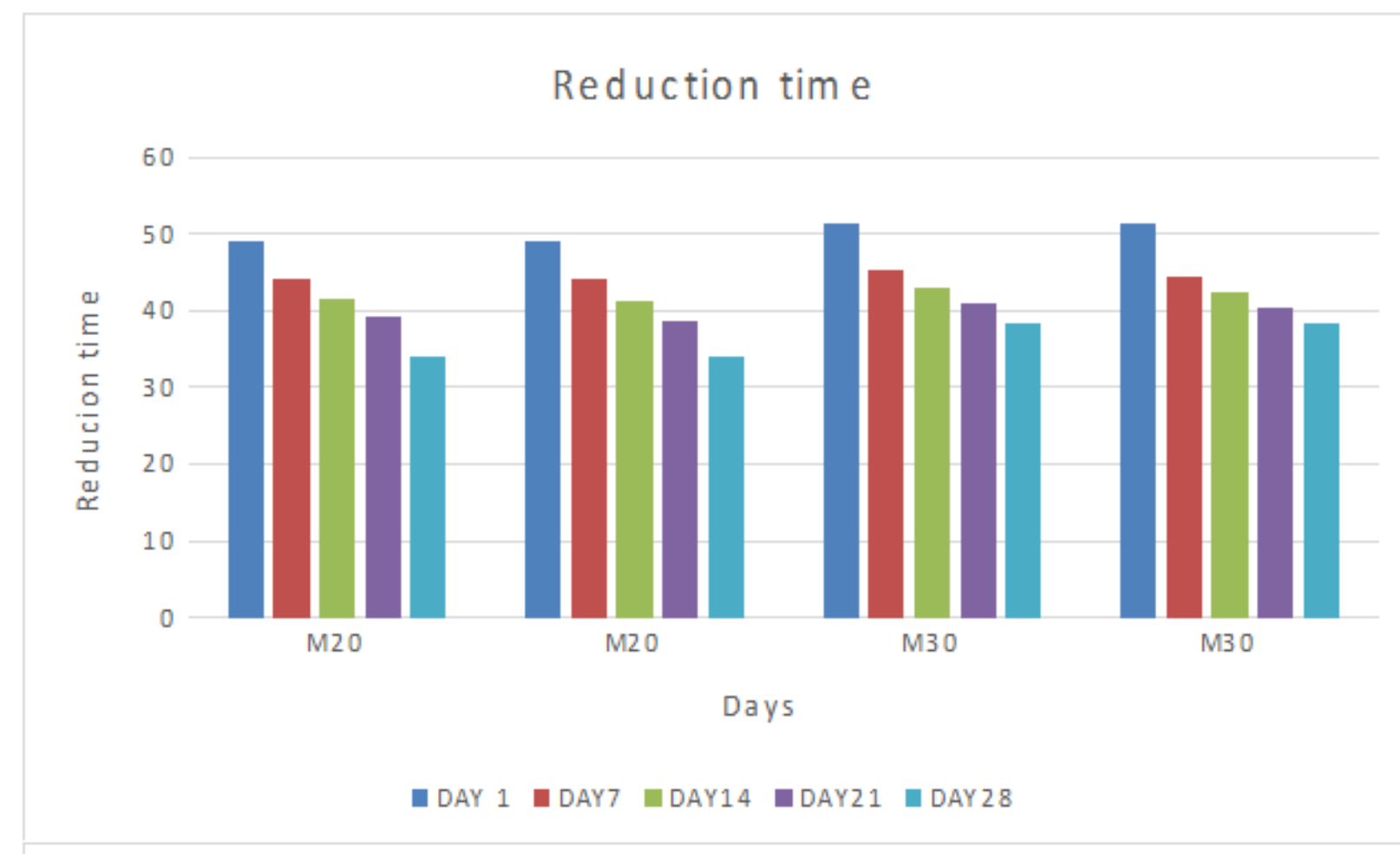

Transm ission tem erature

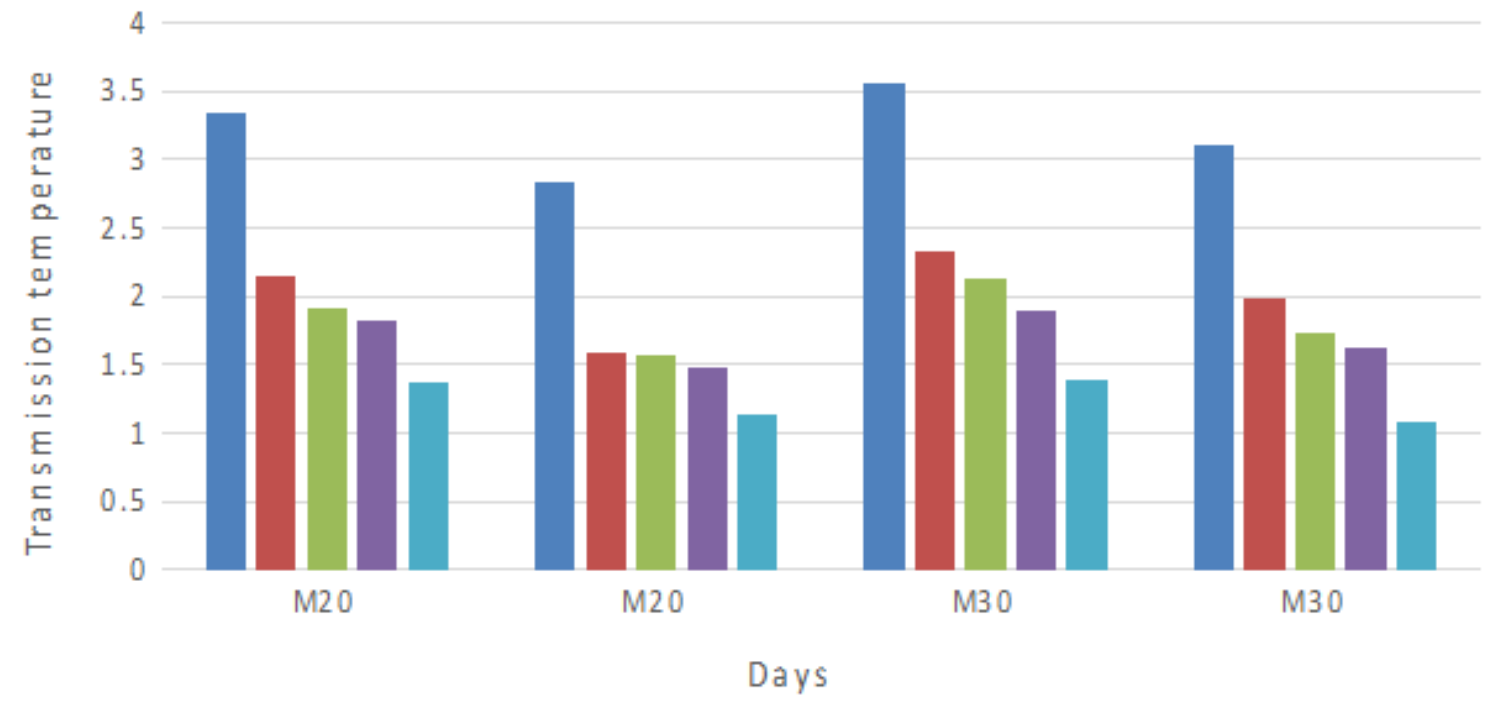

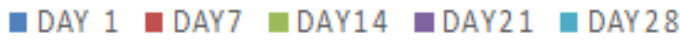




\section{Conclusions \& Recommendations}

From the fig(1) it is observed that the compressive strength has increased by using glass powder as admixture as 20.49 and 28.67 M Pa compared to normal Portland cement gaining 19.71 and $27.72 \mathrm{M} \mathrm{Pa}$ compressive strength for 28 days, by using M20 and M30 grade of concrete.

From the fig (2) it is clear that flexural strength of concrete using glass powder as admixture is greater that is 6.19 and $8.51 \mathrm{M}$ Pa than ordinary Portland cement with 5.78 and $8.17 \mathrm{M} \mathrm{Pa}$. By M20 and M30 grade concrete, for 28 days respectively.

From fig (4) the transmitted temperature from glass powder concrete is less that is 1.130c and $1.090 \mathrm{c}$ where ordinary Portland cement transmits about 1.370c and 1.390c respectively for M20 and M30 grade concrete.

Fig (3) shows, time taken by each simple cool down from 1000c to 400c. The present study reveals that glass powder concrete takes less time that is $34 \mathrm{~min} 4 \mathrm{sec}$ and $38 \mathrm{~min} 31 \mathrm{sec}$ comparatively to the normal concrete $34 \mathrm{~min} 4 \mathrm{sec}$ and $38 \mathrm{~min} 48 \mathrm{sec}$, by M20 and M30 grade concrete respectively. Hence it says the temperature liberated during chemical reaction is less in glass powder admixture concrete cube.

Hence glass powder is best admixture that can be recycled, reused and helps in increasing concrete strength, decreasing reaction temperature.

\section{Acknowledgements}

Special thanks for Gautham Gadgihalli, Hithesh Nagothu, Megha.R for helping me in completing this work successfully. And I also thank my parents, teachers, friends and all elders who supported me.

\section{References}

[1] Lewis, Peter Rhys (2016-06-09) forensic polymer engineering: why polymer products fast in service. Wood head publishing ISBN 978-0-08-100728-0.

[2] Glass-chemistry encyclopedia" Retrieved 1 April 2015".

[3] Jiang, xin ; Lousteau, Joris; Richards, Billy; Jha, Animesh (2009-09-01) “ Investigation on germanium oxide-based glasses for infrared optical fiber development optical materials. 302(11): 1707-1706. Doi; 10.1016/j.optimat.2009.04.011.

[4] Mining the sea sand. Sea friends.org.nz (1994-02-08). Retrieved 2012-05-15.

[5] Shanmugapriya T, Uma R.N: Optimum of partial replacement of M-sand by Natural Sand in high performance concrete with silica fume, 2, 2012, 75.

[6] Ramazan Demirboga, Rumstem Gul: The effect of expanded perlitre aggregate, Silica fume and fly ash on the thermal conductivity of lightweight concrete: 33(5), 2003, 723-727

*Corresponding author.

E-mail address: g.vishal1912@ gmail.com 